REVIEW

\title{
Mifepristone (RU 486) in Cushing's syndrome
}

\author{
Sarah Johanssen and Bruno Allolio \\ Endocrine and Diabetes Unit, Department of Internal Medicine I, University of Wuerzburg, Josef-Schneider-Street 2, 97080 Wuerzburg, Germany \\ (Correspondence should be addressed to B Allolio; Email: allolio_b@medizin.uni-wuerzburg.de)
}

\begin{abstract}
Context: Mifepristone (RU 486) blocks the action of cortisol by binding to the glucocorticoid receptor and, therefore, is of potential therapeutic value in Cushing's syndrome. However, research in endogenous hypercortisolism has been hampered by the controversy related to the use of mifepristone for inducing abortion. Currently, new studies are planned to better define the role of RU 486 in Cushing's syndrome. This paper reviews the available evidence concerning the therapeutic effects and adverse events of RU 486 in Cushing's syndrome.

Evidence acquisition: Original articles and reviews were identified using a PubMed search strategy covering the time period until February 2007.

Evidence synthesis: Treatment of Cushing's syndrome with mifepristone has been reported in a total of 18 patients, with daily doses ranging from 5 to $30 \mathrm{mg} / \mathrm{kg}$. Case reports indicate that the mifepristone-induced receptor blockade may lead to significant clinical improvement in patients with Cushing's syndrome in whom surgery and inhibitors of adrenal steroidogenesis fail to control hypercortisolism. Due to its rapid onset of action, mifepristone may be particularly useful in acute crises, e.g. in cortisol-induced psychosis. Side effects include adrenal insufficiency and, as a result of its antiprogestin action, endometrial hyperplasia in long-term treatment. Adrenal insufficiency can be assessed only by careful clinical evaluation, as the hormonal parameters are not reliable during receptor blockade, and is rapidly reversed by exogenous dexamethasone. Well-designed larger clinical trials are needed to better assess the value of this interesting drug in the treatment of Cushing's syndrome.
\end{abstract}

European Journal of Endocrinology 157 561-569

\section{Introduction}

Mifepristone (RU 486) is the first glucocorticoid receptor (GR) antagonist developed for clinical testing, and it is still the only drug with this property used in humans.

Mifepristone was discovered in the early 1980s at the French pharmaceutical company RU (RousselUclaf) as part of a special research project to develop antiglucocorticoid compounds $(1,2)$. It soon became evident that the compound with the code name Roussell-Uclaf 38 486, later shortened to RU 486, also possessed strong antiprogestin activity. This led investigators to explore the effects of this new drug mainly in progesterone-dependent conditions, e.g. in pregnancy. It was found that the combination of mifepristone with a prostaglandin resulted in complete abortion in almost $100 \%$ of cases. These findings were so impressive that RU 486 became primarily known as the 'abortion pill', although a multitude of potential clinical applications had been predicted at its discovery. Many other usages have been tested, but so far only in preliminary studies, as research projects were strongly hampered by the political controversy surrounding the 'abortion pill' (3).
To date, mifepristone is approved in several countries for medical termination of pregnancy and for cervical dilatation prior to surgical termination of pregnancy. In no country, however, it has been approved for the use in clinical conditions with hypercortisolism. In Cushing's syndrome caused by ectopic adrenocorticotrophin (ACTH)-producing tumours or adrenocortical carcinoma, surgical resection of the tumour can often only partially or temporarily control glucocorticoid hypersecretion. All drugs currently used for control of hypercortisolism in this setting, including ketoconazole, aminoglutethimide, metyrapone and mitotane, decrease adrenal steroid secretion and are frequently associated with significant side effects. A GR antagonist would therefore be an attractive alternative treatment option, and the studies are underway to better define the use of RU 486 in Cushing's syndrome. We here, therefore, review the antiglucocorticoid actions of RU 486 and the hitherto existing clinical experience concerning its use in Cushing's syndrome. Original articles and reviews were identified using a PubMed search strategy covering the time period until February 2007. The following search terms were used in varying combinations: mifepristone, RU 486, Cushing's 
syndrome, hypercortisolism, glucocorticoid, side effects and long-term treatment. In addition, several book chapters related to mifepristone and a conference presentation were used.

\section{Pharmacokinetics}

Mifepristone (11-[4-(dimethylamino)phenyl]-17-hydroxy-17-[1-propynyl]-[11 $\beta, 17 \beta]$-oestra-4,9-diene-3-one; Fig. 1) is a derivative of the synthetic progestin norethindrone. After oral ingestion, the drug is quickly absorbed, and peak serum concentrations in the micromolar range are reached within 1-2 h (4-7). After doses ranging from 50 to $100 \mathrm{mg}$, the serum concentration increases progressively, but little or no further increase is seen after doses of 100-800 mg. The concentrations of several metabolites, in contrast, increase in a dose-dependent manner and exceed that of the parent compound when large doses of RU 486 are administered $(7,8)$. Mifepristone is highly protein bound in human serum, unlike in rats, due to the presence of $\alpha 1$-acid glycoprotein (orosomucoid). Progressive saturation of this high-affinity binding protein may contribute to the non-linear pharmacokinetics of RU 486, since the unbound mifepristone is rapidly metabolized in the liver by demethylation and hydroxylation or is extravasated into tissues. The initial steps in the metabolic process are catalysed by the cytochrome P450 enzyme CYP3A4, and the metabolites are excreted with the faeces (9).

The plasma half-life of mifepristone has been reported to vary between 24 and $48 \mathrm{~h}$ when analysed by high performance liquid chromatography (HPLC), and between 55 and $90 \mathrm{~h}$ when RIA or radioreceptor assays are used. Even if these values were most likely altered by the presence of cross-reacting metabolites, RU 486 exhibits an unusual long plasma half-life when compared with other steroids, which range from minutes (progesterone) to $3-5 \mathrm{~h}$ (dexamethasone) $(9,10)$. This characteristic can also be explained by the extensive binding of the drug. The metabolites also have a long half-life and, to a lesser extent, they also exhibit biological activity (10).

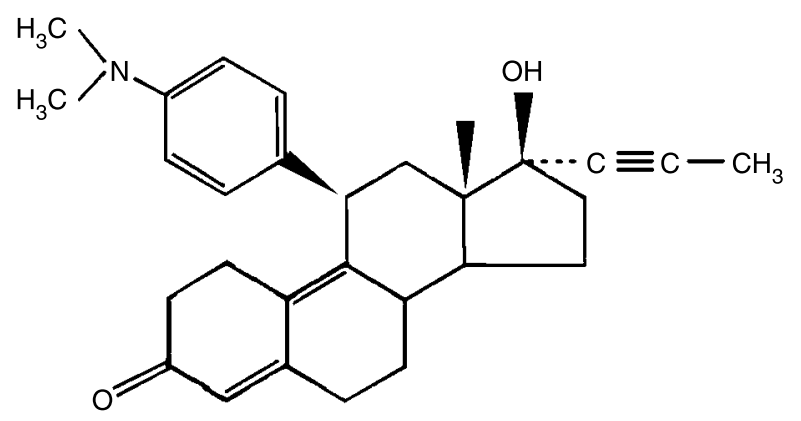

Figure 1 Chemical structure of Mifepristone.

\section{Mechanisms of action}

Mifepristone binds to the human GR with an affinity three to four times higher than that of dexamethasone and about 18 times higher than that of cortisol (11). Binding of mifepristone to the receptor hinders the receptor from releasing from the associated heat shock proteins, thus preventing translocation of the RU 486/ receptor complex to the nucleus. Some of the complexes, however, manage to reach the target DNA, but then transcriptional activity is significantly diminished (12).

The antiglucocorticoid effects of mifepristone are dose dependent. They occur at single doses of $4 \mathrm{mg} / \mathrm{kg}$ and higher, whereas antiprogestin activity is already apparent at much lower doses $(13,14)$. Since mifepristone blocks the GR in a competitive manner, the effect can be reversed by glucocorticoid administration. Precisely, $1 \mathrm{mg}$ dexamethasone abolishes the effects of $400 \mathrm{mg}$ RU 486. However, the antiglucocorticoid effect of RU 486 reappears 1 day later due to its long plasma half-life (15).

Besides its antiglucocorticoid and antiprogestin activity, mifepristone is also a weak antiandrogen. The relative binding affinities of mifepristone for the progesterone receptor and the androgen receptor are five times higher than for progesterone and four times lower than for testosterone respectively. In contrast, mifepristone does not bind to mineralocorticoid and oestradiol receptors (13).

In the absence of endogenous or exogenous glucocorticoids, mifepristone also exhibits some glucocorticoid agonist activity, as shown by Laue (16). After a short period of glucocorticoid deprivation, patients with primary adrenal insufficiency received an oral dose of either placebo, hydrocortisone or mifepristone, followed by a corticotrophin-releasing hormone (CRH) stimulation test. CRH induced significant elevation of plasma ACTH in all placebo-treated patients, whereas hydrocortisone led to significant suppression of the ACTH response. RU 486 caused some suppression of the ACTH response. Its agonist activity was calculated to be about $1 / 250$ th of that of cortisol. However, mifepristone was unable to prevent fatal adrenal insufficiency in adrenalectomized monkeys (17). Thus, glucocorticoid antagonism is the predominant action in vivo.

Mifepristone affects both the central actions of cortisol (its negative feedback on CRH/ACTH secretion) and its peripheral actions. In animals and humans with an intact hypothalamic-pituitary-adrenal (HPA) axis, RU 486 antagonizes the negative feedback of cortisol by blocking central GRs $(2,18)$. The increase in plasma ACTH and cortisol levels induced by RU 486 is particularly evident in the early morning hours, when ACTH and cortisol concentrations are physiologically peaking (19). Mifepristone also antagonizes the dexamethasone-induced cortisol suppression (2). Although long-term administration of RU 486 produces persistent elevation of ACTH and cortisol levels, the response to 
CRH and the circadian rhythm of ACTH and cortisol secretion are not affected. Thus, the central regulatory mechanisms remain intact (20).

Concerning the peripheral actions of cortisol, it was shown in healthy volunteers that mifepristone antagonizes acute effects of cortisol on protein and glucose metabolism (21). In addition, RU 486 inhibits the cortisol-induced peripheral vasoconstriction that was demonstrated by attenuated skin blanching after administration of topical steroids (22). A slight increase in circulating eosinophils during treatment with RU 486 was also reported in some, but not in all, studies.

In a study by Bertagna et al. ten healthy male volunteers were given RU 486 at a daily dose of $200 \mathrm{mg}$ $(\sim 3 \mathrm{mg} / \mathrm{kg}$ ) for 8 days $(23)$. The treatment resulted in a clear activation of the HPA axis, demonstrated by elevated ACTH and cortisol levels. This biochemically detectable antiglucocorticoid effect was not accompanied by relevant clinical symptoms of adrenal insufficiency. Bertagna and colleagues concluded that in subjects with an intact HPA axis, the central effect of the drug (upregulation of the HPA axis) prevents peripheral glucocorticoid deficiency by maintaining an adequate equilibrium between endogenous cortisol levels and circulating RU 486. Bertagna and his team also investigated the response of the HPA axis to RU 486 in patients with Cushing's syndrome (24). Five patients with Cushing's disease and two patients with nonpituitary Cushing's syndrome received $400 \mathrm{mg}$ mifepristone daily on 3 consecutive days. In all patients with Cushing's disease, RU 486 administration was associated with further stimulation of the already activated HPA axis, particularly demonstrated by a marked increase in urinary cortisol excretion. In the two patients with non-pituitary Cushing's syndrome, in contrast, no significant changes in hormone secretion were observed after administration of RU 486. Thus, the hormonal response to mifepristone in Cushing's syndrome depends on the underlying cause of hypercortisolism. Unlike persons with an intact HPA axis, there were two patients with Cushing's disease who developed potential signs of glucocorticoid insufficiency (nausea and headache in one case and lethargy in the other case) and who had to be treated with dexamethasone.

\section{RU 486 in Cushing's syndrome}

Up to now, 18 patients have been reported to have received RU 486 for treatment of hypercortisolism (for an overview, see Table 1).

The first patient, a 25-year-old male with ectopic ACTH syndrome due to an intrathoracic carcinoid tumour, was reported by Nieman in 1985 (25). The initial dose of $5 \mathrm{mg} / \mathrm{kg}$ mifepristone per day was increased every 1-2 weeks to a maximum of $20 \mathrm{mg} / \mathrm{kg}$. The clinical signs of hypercortisolism - namely central obesity, high blood pressure, hypokalaemic alkalosis, elevated plasma glucose levels and depression - clearly improved during treatment with RU 486. No side effects were observed. After 9 weeks, RU 486 was no longer available, and the treatment had to be stopped. To control hypercortisolism, bilateral adrenalectomy was performed.

In the following years, Nieman and co-workers studied the effects of RU 486 in ten more patients with Cushing's syndrome $(26,27)$. In six of them, the clinical response was excellent, and the treatment was generally well tolerated. However, in the remaining four patients, treatment with RU 486 had to be stopped after 3-14 days because of adverse events. These included severe nausea, prostration and hypotension. One patient developed Pneumocystis carinii pneumonia.

Treatment duration in the above six other cases - four cases with ectopic ACTH syndrome, one adrenal adenoma and one adrenocortical carcinoma - ranged from 6 weeks to 12 months. Mifepristone was applied in doses ranging from 5 to $22 \mathrm{mg} / \mathrm{kg}$ per day. Reported side effects included moderate nausea, development of gynecomastia, impotence and Hashimoto's thyroiditis. There was one episode of adrenal insufficiency in a 63-year-old woman with ectopic ACTH syndrome. In most patients, plasma ACTH and cortisol remained significantly elevated, but unlike the reports in subjects with an intact HPA axis, these patients had no further increase in ACTH and cortisol levels. Intriguingly, in two patients, plasma and urinary cortisol levels even decreased while plasma ACTH levels remained unchanged, so that inhibition of adrenal cortisol synthesis by mifepristone was suggested $(26,27)$.

Van der Lely reported two patients with adrenal carcinoma in whom RU 486 reversed acute cortisolinduced psychosis within $24 \mathrm{~h}$ (28). Both patients died some weeks later due to tumour progression. There were two other cases of adrenocortical carcinoma treated with RU 486, but only limited information on these patients has been provided $(29,30)$.

In Cushing's disease, the HPA axis is characterized by an upregulated set point, and patients with Cushing's disease also react to RU 486 with further activation of the HPA axis. This may limit the therapeutic value of RU 486 in such patients, because a mifepristone-induced increase in ACTH and cortisol levels may overcome the receptor blockade. However, in one patient with an ACTH-secreting pituitary macroadenoma, treatment with RU 486 resulted in clear clinical improvement (31). The patient was a 51-year-old, severely ill male suffering from cortisol-induced psychosis, multiple metabolic disturbances and cardiomyopathy. Transsphenoidal resection of the tumour was incomplete, ketoconazole was not tolerated and mitotane failed to control hypercortisolism. The patient underwent pituitary irradiation, and treatment with RU 486 was initiated to bridge the time until radiotherapy would show benefit. Cardiomyopathy, psychosis and the metabolic disturbances improved impressively. In the 
Table 1 Patients with Rousell-Uclaf 38486 (RU 486) therapy for Cushing's syndrome.

\begin{tabular}{|c|c|c|c|c|c|c|}
\hline Patient & Disease & RU 486 dosage & $\begin{array}{l}\text { Duration of } \\
\text { treatment }\end{array}$ & Response & Side effects & Reference \\
\hline 25 years, male & EAS & $5-20 \mathrm{mg} / \mathrm{kg}$ daily & 9 weeks & Clinical improvement & No side effects observed & $(25-27)$ \\
\hline $\begin{array}{l}27 \text { months, } \\
\text { female }\end{array}$ & EAS & $\begin{array}{l}25 \mathrm{mg} \text { thrice daily } \\
(\approx 5 \mathrm{mg} / \mathrm{kg}) \text { to } \\
100 \mathrm{mg} \text { thrice } \\
\text { daily }\end{array}$ & 2 months & Clinical improvement & No side effects observed & (34) \\
\hline 36 years, male & EAS & $5-22$ mg/kg daily & 10 months & Clinical improvement & $\begin{array}{l}\text { Hashimoto's thyroiditis, } \\
\text { gynecomastia, } \\
\text { impotence, 'inhibition of } \\
\text { cortisol synthesis' }\end{array}$ & $(26,27)$ \\
\hline $\begin{array}{l}45 \text { years, } \\
\text { female }\end{array}$ & ACC & & 2 months & Clinical improvement & No side effects observed & $(26,27)$ \\
\hline $\begin{array}{l}38 \text { years, } \\
\text { female }\end{array}$ & AA & & 6 weeks & Clinical improvement & Nausea & $(26,27)$ \\
\hline 42 years, male & EAS & & 12 months & Clinical improvement & Nausea, gynecomastia & $(26,27)$ \\
\hline $\begin{array}{l}63 \text { years, } \\
\text { female }\end{array}$ & EAS & & 4 months & Clinical improvement & Adrenal crisis & $(26,27)$ \\
\hline $\begin{array}{l}55 \text { years, } \\
\text { female }\end{array}$ & EAS & & 10 weeks & Clinical improvement & No side effects observed & $(26,27)$ \\
\hline NR & NR & NR & $<1$ month & - & Hypotension & $(26,27)$ \\
\hline NR & NR & NR & $<1$ month & - & $\begin{array}{l}\text { Pneumocystis carinii } \\
\text { pneumonia }\end{array}$ & $(26,27)$ \\
\hline NR & NR & NR & $<1$ month & - & Severe nausea, prostration & $(26,27)$ \\
\hline NR & NR & NR & $<1$ month & - & $\begin{array}{l}\text { Nausea, 'inhibition of } \\
\text { cortisol biosynthesis' }\end{array}$ & $(26,27)$ \\
\hline $\begin{array}{l}14 \text { years, } \\
\text { female }\end{array}$ & NCS & 400 mg daily & $\begin{array}{l}8 \text { months (with } \\
\text { interruptions) }\end{array}$ & Clinical improvement & $\begin{array}{l}\text { Endometrial hyperplasia, } \\
\text { transient rash, } \\
\text { Hashimoto's thyroiditis }\end{array}$ & (32) \\
\hline 51 years, male & CD & $\begin{array}{l}400-2000 \mathrm{mg} \text { daily } \\
(\approx 25 \mathrm{mg} / \mathrm{kg})\end{array}$ & 18 months & Clinical improvement & $\begin{array}{l}\text { Severe hypokalaemia, } \\
\text { adrenal crisis }\end{array}$ & (31) \\
\hline 43 years, male & ACC & $\begin{array}{l}800 \mathrm{mg} \text {, dose } \\
\text { reduction to } \\
400 \mathrm{mg} \text { daily }\end{array}$ & 2 weeks & $\begin{array}{l}\text { Mental abnormalities } \\
\text { disappeared within } \\
24 \mathrm{~h}\end{array}$ & $\begin{array}{l}\text { Hypoglycaemic episodes, } \\
\text { increase in eosinophils }\end{array}$ & (28) \\
\hline $\begin{array}{l}32 \text { years, } \\
\text { female }\end{array}$ & ACC & 400 mg daily & 2 months & $\begin{array}{l}\text { Mental abnormalities } \\
\text { improved within } \\
24 \mathrm{~h}\end{array}$ & No side effects observed & $(26,27)$ \\
\hline Female & ACC & $\begin{array}{l}30 \mathrm{mg} / \mathrm{kg} \text { daily, } \\
\text { dose reduction } \\
\text { to } 20 \mathrm{mg} / \mathrm{kg} \text { per } \\
\mathrm{KG}\end{array}$ & 4 months & $\begin{array}{l}\text { Clinical improvement, } \\
\text { tumour regression }\end{array}$ & $\begin{array}{l}\text { Vaginal bleeding, hypogly- } \\
\text { caemia, water retention }\end{array}$ & (29) \\
\hline 62 years, male & ACC & 400 mg daily & 9 months & $\begin{array}{l}\text { Initial improvement of } \\
\text { hypokalaemic alka- } \\
\text { losis and diabetes, } \\
\text { but after } 9 \text { months } \\
\text { clinical hypercorti- } \\
\text { solism recurred } \\
\text { due to tumour } \\
\text { growth }\end{array}$ & NR & (30) \\
\hline
\end{tabular}

AA, adrenal adenoma; ACC, adrenocortical carcinoma; CD, Cushing's disease; CS, Cushing's syndrome; EAS, ectopic ACTH syndrome; NCS, normocortisolaemic Cushing's syndrome; NR, not reported.

course of the treatment, the patient developed severe hypokalaemia, and spironolactone therapy was initiated. It was suggested that hypokalaemia resulted from stimulation of the mineralocorticoid receptor by cortisol, while GRs were blocked by mifepristone. The patient also experienced one episode of adrenal insufficiency, manifested by weakness, orthostatic hypotension and hypoglycaemia, which resolved after administration of i.v. dexamethasone. During treatment with RU 486, plasma ACTH and cortisol levels were fluctuating but remained elevated over a period of about 8 months. Then the ACTH and cortisol levels decreased, probably due to the delayed effects of radiotherapy, and mifepristone therapy was tapered down over the following 10 months.

The remaining two cases described in the literature were peculiar cases of transient hypercortisolism. One was a 14-year-old girl suffering from a so-called normocortisolaemic Cushing's syndrome, showing typical clinical features of hypercortisolism (central obesity, purple striae and reduced bone density) but normal cortisol levels (32). Investigators reported an increased amount of GR sites per cell. Treatment with RU 486 resulted in improvement of obesity and striae 
but was without effect on bone. The treatment had to be interrupted several times because of vaginal bleeding. After 8 months of treatment, massive amorphous material was found in the distended uterus. Curettage followed and showed endometrial hyperplasia (33). The Cushingoid features continued to resolve gradually after withdrawal of RU 486. The other case was a 27-monthold baby girl in whom an ACTH-depending Cushing's syndrome was suspected but no tumour could be detected (34). Treatment with RU 486 caused significant improvement of central obesity, blood pressure and blood glucose levels. Plasma and urinary cortisol and, to a lesser extent, ACTH decreased. Treatment with RU 486 was stopped after 2 months. Interestingly, no clinical nor biochemical relapse occurred so that the cause of Cushing's syndrome remains elusive.

\section{Side effects in short-term use}

Termination of unwanted pregnancies with a single $600 \mathrm{mg}$ dose of mifepristone followed by a prostaglandin analogue is generally well tolerated (35). The most frequent side effects include abdominal pain, cramping, nausea, vomiting and headache, and it is difficult to discriminate these symptoms from sensations that occur during spontaneous abortion. Some of the reported side effects are more likely associated with the prostaglandin used than with mifepristone. The abdominal pain, for example, is significantly less when using the mifepristone-prostaglandin combination compared with abortive regimens using prostaglandins alone (36). There were also several serious cardiovascular events, including a fatal acute myocardial infarction, that were attributed to the prostaglandin component of the treatment. The prostaglandin analogue used in these cases, sulprostone i.m., has been withdrawn from the market (14).

Only very few women do not abort after treatment with mifepristone plus prostaglandin. In these rare cases, however, possible teratogenic effects of the drugs administered would be of great importance. In contrast to prostaglandins, mifepristone had no teratogenic effects in animal studies (37). Rabbits, however, showed cephalic deformities that were explained by mechanical damage due to uterine contractions, resulting from the decrease in progesterone activity (36).

The doses of RU 486 needed to exhibit antiglucocorticoid effects are significantly higher than those needed for antiprogestin activity. Thus, in women receiving a single dose of mifepristone for termination of pregnancy, no clinically relevant antiglucocorticoid side effects have been reported (27).

\section{Side effects in long-term use}

Chronic administration of mifepristone has been tested in the patients with Cushing's syndrome described above previously, but these were only reports of individual cases. Larger studies have been performed in patients with unresectable meningioma, endometriosis, myoma and breast cancer. As these trials aimed at progesterone receptor blockade and not GR blockade, much lower doses were administered, which probably facilitated the availability of RU 486. Treatment duration varied from several weeks or months up to 14 years and was longest in patients with meningioma. Information on safety of longterm treatment with mifepristone is mainly provided by these pilot studies (Table 2).

\section{Antiglucocorticoid side effects}

Daily doses of mifepristone ranged from 5 to $100 \mathrm{mg}$ in myoma and endometriosis studies, and from 200 to $400 \mathrm{mg}$ in meningioma and breast cancer (38). These rather low doses had been chosen to avoid antiglucocorticoid effects while achieving full antiprogestin activity. However, repeated administration of even these low doses resulted in an activation of the HPA axis, which was demonstrated by elevated plasma ACTH and cortisol levels $(20,23,38)$.

Spitz and Grunberg reported 28 patients with unresectable meningioma who received continuous treatment with $200 \mathrm{mg}$ mifepristone daily for up to 13 years (39-41). Patients received concomitant dexamethasone therapy for the first 14 days. The most common side effect was fatigue, which was

Table 2 Side effects of long-term treatment with mifepristone depending on the blocked receptor and the doses administered.

\begin{tabular}{lll}
\hline Receptor & Daily dose & Potential side effects \\
\hline PR & $>5 \mathrm{mg}$ & Amenorrhoea \\
& $>10 \mathrm{mg}$ & Endometrial hyperplasia \\
GR & $>50 \mathrm{mg}$ & Increase in cortisol, ACTH, adrenal androgens \\
& $>100-200 \mathrm{mg}$ & Mild to moderate fatigue/nausea \\
& $>200-400 \mathrm{mg}$ & Adrenal insufficiency (severe nausea, severe fatigue and other symptoms) \\
& $>200 \mathrm{mg}$ & Gynecomastia (due to elevated oestradiol levels derived from adrenal androgens) \\
& $>200 \mathrm{mg}$ (isolated cases) & Hypokalaemia (due to MR activation by cortisol?) \\
AR & $>400 \mathrm{mg}$ (isolated cases) & Hypothyroidism \\
& $>200 \mathrm{mg}$ & Gynecomastia, decrease in libido
\end{tabular}

Dose designations are estimated based on the results from long-term trials, exact doses at which the listed side effects occur may vary between individuals. PR, progesterone receptor; GR, glucocorticoid receptor; AR, androgen receptor; MR, mineralocorticoid receptor. 
generally mild. Clinically relevant adrenal insufficiency only occurred in one patient who was already on glucocorticoid replacement for known hypopituitarism. Her symptoms resolved after increasing the exogenous steroid replacement. Lamberts, however, who investigated the effects of daily administration of mifepristone $(200 \mathrm{mg})$ in ten patients with meningioma reported that in four patients prednisone therapy had to be initiated in order to overcome the side effects (20). De Keizer and colleagues, who treated two women with meningioma with 200-400 mg mifepristone daily for up to 14 years, combined mifepristone therapy from the start with concomitant glucocorticoid administration to prevent adrenal insufficiency (42). In the myoma and endometriosis studies, however, where much lower doses of mifepristone were administered (5-100 mg), antiglucocorticoid side effects seemed to be of minor importance, as no episodes of adrenal insufficiency were reported. In summary, clinical adrenal insufficiency must be considered a possible side effect of long-term treatment with mifepristone, but is a rare complication in patients with an intact HPA axis. The drug-induced compensatory hypersecretion of ACTH and cortisol seems to prevent the risk of peripheral cortisol deficiency. Some patients with progesterone-dependent diseases, however, may benefit from concomitant glucocorticoid therapy to better tolerate long-term treatment with mifepristone.

In the 18 patients with Cushing's syndrome described above previously, there were five events of adrenal insufficiency (presumed that the reported episodes of severe nausea, prostration and marked hypotension were indicative of acute adrenal insufficiency). Thus, the rate of adrenal insufficiency related to the GR blockade seems to be higher in patients with Cushing's syndrome than in patients with meningioma, myoma or other progesterone-dependent diseases. Several factors may contribute to this problem. First, the doses used were markedly higher. Secondly, the HPA axis is altered in these patients, and its response to GR blockade is more difficult to predict. In particular, hypothalamic CRH secretion is typically severely impaired in Cushing's syndrome hampering the adaptation to deficient glucocorticoid action. In addition, there are no biochemical markers for assessment of glucocorticoid insufficiency during treatment with RU 486, as measurement of plasma ACTH and plasma or urinary cortisol is not reliable, and the balance between desired antiglucocorticoid action and overtreatment is difficult to maintain.

\section{Endometrial hyperplasia}

A problem in long-term treatment with mifepristone is the complex influence of this drug on the endometrium. On one hand, mifepristone exhibits antiproliferative effects, of what is taken advantage in its use in myoma and endometriosis. On the other hand, mifepristone is associated with frequent development of endometrial hyperplasia.

In several studies, treatment with 5-50 mg mifepristone led to a marked reduction in myoma volume, with significant relief from pain and bleeding $(38,43,44)$. It is supposed that blockade of progesterone-dependent growth factors, reduced blood supply due to vascular changes and decreased inhibition of oestrogen receptor gene transcription by the progesterone receptor A isoform are some of the mechanisms contributing to the antiproliferative activity of mifepristone (44).

Concerning endometrial hyperplasia, we have already mentioned detection of extensive hyperplasia in an adolescent girl with Cushing's syndrome after 8 months of treatment with RU 486 (33). In the meningioma study of Spitz et al., the incidence of endometrial hyperplasia was reported to be about $10 \%$ (39). In women suffering from myoma, Eisinger reported a rate of endometrial hyperplasia of $25 \%$ after 6 months of treatment with $10 \mathrm{mg}$ mifepristone daily (43). The mechanisms involved in these proliferative effects are not completely understood, and the histological changes differ from classical forms of endometrial hyperplasia (45). When low doses of RU 486 (5-50 mg daily) are administered, hyperplasia seems to be the result of unopposed oestradiol action on the endometrium due to progesterone receptor blockade. With higher doses, activation of the HPA axis may also play a role (44). It has been shown that the drug-induced rise in plasma ACTH is followed by an increase in not only plasma cortisol, but also adrenal androgens and oestradiol. The increased oestradiol levels may derive from peripheral aromatization of adrenal androgens and may also contribute to proliferation of the endometrium $(20,44,46,47)$.

So far, no case of endometrial carcinoma has been reported in relation to long-term treatment with mifepristone, and the risk seems to be rather low (43). However, regular vaginal ultrasound for monitoring of endometrial hyperplasia is recommended in women receiving long-term treatment with mifepristone.

\section{Effects on biochemical parameters}

Occasionally, long-term administration of mifepristone has been associated with low serum potassium levels, a slight increase in serum creatinine levels or moderate elevation of hepatic enzymes $(43,44,48)$.

Depending on the dose and treatment duration, longterm administration of mifepristone may also be associated with alterations in thyroid homeostasis. Thyrotrophin (TSH) levels may increase significantly but in most cases remain within the normal range. Since glucocorticoids suppress pituitary TSH secretion, increased TSH levels might be related to central antiglucocorticoid effects of mifepristone. Direct effects within the thyroid gland itself, leading to a compensatory increase in TSH levels, were also suggested (49). 
In individual cases, development of Hashimoto's thyroiditis has been reported $(26,27,32)$.

\section{Other side effects}

Other side effects reported during long-term treatment with RU 486 include anorexia, weight loss, dizziness, amenorrhoea, hot flushes and transient thinning of the hair (36). Some men complained of gynecomastia and a decrease in libido. These latter side effects were probably related to binding of mifepristone to the androgen receptor and to elevated oestradiol levels.

Another adverse event reported was a grand mal seizure with impaired consciousness in a woman with breast cancer. At first, the grand mal seizure was thought to be caused by cerebral metastases, but no metastases were detected with computed tomography. After withdrawal of mifepristone and initiation of dexamethasone therapy, the patient significantly improved within 3 days (46).

The daily mifepristone doses administered in the patients with Cushing's syndrome ranged from 400 to $2000 \mathrm{mg}$. Besides this patient group, comparable doses were administered only in a group of 11 healthy male volunteers (50). Subjects were planned to receive RU 486 at a daily dose of $10 \mathrm{mg} / \mathrm{kg}$ over a period of 14 days. However, the study had to be revised because of a high incidence of adverse events. One subject developed acute adrenal insufficiency after 10 days of treatment with RU 486 and had to be treated with dexamethasone. Eight out of eleven subjects developed a generalized exanthema after 9-10 days of treatment. In all cases, the rash spontaneously resolved after withdrawal of mifepristone. This high incidence of skin rashes was not observed in other studies. In women receiving singledose administration of $600 \mathrm{mg}$ mifepristone, the rate of rashes was below $1 \%$ (14). In patients with Cushing's syndrome, who received comparable doses of mifepristone, there was only one case of transient rash (32). It was suggested that the hypercortisolism in these patients may have had a protective effect against such a hypersensitivity reaction (50).

\section{Monitoring}

General recommendations for monitoring of patients on long-term treatment with mifepristone include annual vaginal ultrasound in women and annual control of TSH and thyroid hormones in women and men (39).

Adrenal insufficiency can only be assessed by clinical observation, as cortisol and ACTH levels are either elevated or within the normal range. As the GRs are blocked, high cortisol levels may cause overstimulation of the mineralocorticoid receptors. Thus, in some cases, serum potassium levels and blood pressure values may be of little help in assessment of adrenal insufficiency. Extreme weakness and fatigue, severe nausea and hypoglycaemic episodes are indicative of peripheral cortisol deficiency, and then glucocorticoids should be given immediately.

Patients with Cushing's syndrome should be monitored with particular attention to clinical signs of adrenal insufficiency, and the dose of RU 486 should be increased only gradually.

\section{Conclusions}

The long-term use of mifepristone as an antiprogestin in myoma, meningioma and other progesterone-dependent diseases is generally well tolerated. In the rare cases with clinically relevant antiglucocorticoid side effects, concomitant glucocorticoid therapy can be initiated. Management of patients with Cushing's syndrome, however, seems to be more demanding. As there are no biochemical markers for adrenal insufficiency during treatment with RU 486, it requires careful clinical observation to establish where the desired antiglucocorticoid action ends and overtreatment starts. The most common starting dose in Cushing's syndrome, $400 \mathrm{mg}$ daily, was deduced from the observation that mifepristone-induced blockade of the GR is dose dependent and becomes apparent only at doses of at least $4-6 \mathrm{mg} / \mathrm{kg}$. Yet, this was derived from studies with single doses. Repeated administration of lower doses also produces antiglucocorticoid effects, as the long-term studies in meningioma, myoma and breast cancer have shown. Hence, doses below $400 \mathrm{mg} /$ day might also be used successfully in the treatment of Cushing's syndrome and may be associated with fewer side effects.

In patients with Cushing's syndrome in whom longterm treatment with mifepristone was, on the whole, well tolerated, improvement of clinical features was impressive. Mifepristone, therefore, remains an interesting treatment option for Cushing's syndrome caused by ectopic ACTH production or adrenocortical carcinoma that cannot be controlled by surgery alone. It may be particularly useful in conditions in which a rapid onset of antiglucocorticoid effects is required, e.g. in acute cortisol-induced psychosis. Regrettably, mifepristone is currently not easily available for treatment of Cushing's syndrome outside of clinical trials, as the disposability of the 'abortion pill' is limited by legal restrictions. Well-designed clinical trials in patients with Cushing's syndrome are urgently needed to better appreciate the therapeutic potential of mifepristone in hypercortisolism.

\section{Acknowledgements}

References (1, 9, 26 and 37) were kindly provided by André Ulmann (HRA Pharma, Paris, France). 


\section{References}

1 Ulmann A, Teutsch G \& Philibert D. RU 486. Scientific American $199026242-48$.

2 Bertagna X, Bertagna C, Luton JP, Husson JM \& Girard F. The new steroid analog RU 486 inhibits glucocorticoid action in man. Journal of Clinical Endocrinology and Metabolism 198459 25-28.

3 Kettel LM. Clinical applications of the antiprogestins. Clinical Obstetrics and Gynecology 199538 921-934.

4 Foldesi I, Falkay G \& Kovacs L. Determination of RU 486 (mifepristone) in blood by radioreceptorassay; a pharmacokinetic study. Contraception 199654 27-32.

5 Kekkonen R, Heikinheimo O, Mandelin E \& Lahteenmaki P. Pharmacokinetics of mifepristone after low oral doses. Contraception $1996 \mathbf{5 4} 229-234$.

6 Lähteenmäki P, Heikinheimo O, Croxatto H, Spitz IM, Shoupe D, Birgerson L \& Luukkainen T. Pharmacokinetics and metabolism of RU 486. Journal of Steroid Biochemistry 198727 859-863.

7 Heikinheimo O, Kontula K, Croxatto H, Spitz I, Luukkainen T \& Lahteenmaki P. Plasma concentrations and receptor binding of RU 486 and its metabolites in humans. Journal of Steroid Biochemistry 198726 279-284.

8 Heikinheimo O, Kekkonen R \& Lahteenmaki P. The pharmacokinetics of mifepristone in humans reveal insights into differential mechanisms of antiprogestin action. Contraception $2003 \mathbf{6 8} 421-426$.

9 Heikinheimo O. Clinical pharmacokinetics of mifepristone. Clinical Pharmacokinetics 199733 7-17.

10 Kawai S, Nieman LK, Brandon DD, Udelsman R, Loriaux DL \& Chrousos GP. Pharmacokinetic properties of the antiglucocorticoid and antiprogesterone steroid RU 486 in man. Journal of Pharmacology and Experimental Therapeutics $1987 \mathbf{2 4 1} 401-406$.

11 Sartor O \& Cutler GB Jr. Mifepristone: treatment of Cushing's syndrome. Clinical Obstetrics and Gynecology 199639 506-510.

12 Bamberger CM \& Chrousos GP. The glucocorticoid receptor and RU 486 in man. Annals of the New York Academy of Sciences 1995761 296-310.

13 Cadepond F, Ulmann A \& Baulieu EE. RU 486 (mifepristone): mechanisms of action and clinical uses. Annual Review of Medicine 199748 129-156.

14 Sitruk-Ware R \& Spitz IM. Pharmacological properties of mifepristone: toxicology and safety in animal and human studies. Contraception 200368 409-420.

15 Raux-Demay MC, Pierret T, Bouvier D'yvoire M, Bertagna X \& Girard F. Transient inhibition of RU 486 antiglucocorticoid action by dexamethasone. Journal of Clinical Endocrinology and Metabolism $199070230-233$.

16 Laue L, Chrousos GP, Loriaux DL, Barnes K, Munson P, Nieman L \& Schaison G. The antiglucocorticoid and antiprogestin steroid RU 486 suppresses the adrenocorticotropin response to ovine corticotropin releasing hormone in man. Journal of Clinical Endocrinology and Metabolism 198866 290-293.

17 Laue L, Gallucci W, Loriaux DL, Udelsman R \& Chrousos GP. The antiglucocorticoid and antiprogestin steroid RU 486: its glucocorticoid agonist effect is inadequate to prevent adrenal insufficiency in primates. Journal of Clinical Endocrinology and Metabolism $198867602-606$.

18 Healy DL, Chrousos GP, Schulte HM, Williams RF, Gold PW, Baulieu EE \& Hodgen GD. Pituitary and adrenal responses to the antiprogesterone and anti-glucocorticoid steroid RU 486 in primates. Journal of Clinical Endocrinology and Metabolism 198357 863-865.

19 Gaillard RC, Riondel A, Muller AF, Herrmann W \& Baulieu EE. RU 486: a steroid with antiglucocorticosteroid activity that only disinhibits the human pituitary-adrenal system at a specific time of day. PNAS 198481 3879-3882.

20 Lamberts SW, Koper JW \& de Jong FH. The endocrine effects of long-term treatment with mifepristone (RU 486). Journal of Clinical Endocrinology and Metabolism 199173 187-191.

21 Garrel DR, Moussali R, de Oliveira A, Lesiege D \& Lariviere F. RU 486 prevents the acute effects of cortisol on glucose and leucine metabolism. Journal of Clinical Endocrinology and Metabolism 1995 80 379-385.
22 Gaillard RC, Poffet D, Riondel AM \& Saurat JH. RU 486 inhibits peripheral effects of glucocorticoids in humans. Journal of Clinical Endocrinology and Metabolism 198561 1009-1011.

23 Bertagna X, Escourolle H, Pinquier JL, Coste J, Raux-Demay MC, Perles P, Silvestre L, Luton JP \& Strauch G. Administration of RU 486 for 8 days in normal volunteers: antiglucocorticoid effect with no evidence of peripheral cortisol deprivation. Journal of Clinical Endocrinology and Metabolism 199478 375-380.

24 Bertagna X, Bertagna C, Laudat MH, Husson JM, Girard F \& Luton JP. Pituitary-adrenal response to the antiglucocorticoid action of RU 486 in Cushing's syndrome. Journal of Clinical Endocrinology and Metabolism 198663 639-643.

25 Nieman LK, Chrousos GP, Kellner C, Spitz IM, Nisula BC Cutler GB, Merriam GR, Bardin CW \& Loriaux DL. Successful treatment of Cushing's syndrome with the glucocorticoid antagonist RU 486. Journal of Clinical Endocrinology and Metabolism $198561536-540$.

26 Chrousos GP, Laue L, Nieman L, Udelsman R, Kawai S \& Loriaux DL. Clinical Applications of RU 486, a Prototype Glucocorticoid and Progestin Antagonist New York: Raven Press, 1989.

27 Chrousos GP, Laue L, Nieman LK, Kawai S, Udelsman RU, Brandon DD \& Loriaux DL. Glucocorticoids and glucocorticoid antagonists: lessons from RU 486. Kidney International. Supplement 198826 S18-S23.

28 van der Lely AJ, Foeken K, Van Der Mast RC \& Lamberts SW. Rapid reversal of acute psychosis in the Cushing syndrome with the cortisol-receptor antagonist mifepristone (RU 486). Annals of Internal Medicine 1991114 143-144.

29 Contreras P. Adrenal cancer: tumor regression with ketoconazole or mifepristone (RU 486). In vivo and in vitro evidence supporting tumoral hormone dependency. Proceedings of the 69th Annual Endocrine Society Meeting, Indianapolis, p 23, 1987.

30 Donckier JE, Michel LA, Berbinschi A, de Coster PM, de Plaen JF, Ketelslegers JM \& Buysschaert M. Late recurrence of operated adrenocortical carcinoma: atrial natriuretic factor before and after treatment with mitotane. Surgery 1989105 690-692.

31 Chu JW, Matthias DF, Belanoff J, Schatzberg A, Hoffman AR \& Feldman D. Successful long-term treatment of refractory Cushing's disease with high-dose mifepristone (RU 486). Journal of Clinical Endocrinology and Metabolism 200186 3568-3573.

32 Newfield RS, Kalaitzoglou G, Licholai T, Chilton D, Ashraf J, Thompson EB \& New MI. Normocortisolemic Cushing's syndrome initially presenting with increased glucocorticoid receptor numbers. Journal of Clinical Endocrinology and Metabolism 200085 14-21.

33 Newfield RS, Spitz IM, Isacson C \& New MI. Long-term mifepristone (RU 486) therapy resulting in massive benign endometrial hyperplasia. Clinical Endocrinology 2001 54 399-404.

34 Beaufrere B, de Parscau L, Chatelain P, Morel Y, Aguercif M \& Francois R. RU 486 administration in a child with Cushing's syndrome. Lancet 19872217.

35 Goldberg JR, Plescia MG \& Anastasio GD. Mifepristone (RU 486): current knowledge and future prospects. Archives of Family Medicine $19987219-222$.

36 Spitz IM \& Bardin CW. Mifepristone (RU 486) - a modulator of progestin and glucocorticoid action. New England Journal of Medicine 1993329 404-412.

37 Deraedt R, Vannier B \& Fournex R. Toxicological study on RU 486. In: The Antiprogestin Steroid RU 486 and Human Fertility Control. pp 105-126, 1985. Eds EE Baulieu \& SJ Segal, New York: Plenum Press 1992.

38 Koide SS. Mifepristone. Auxiliary therapeutic use in cancer and related disorders. Journal of Reproductive Medicine 199843 551-560.

39 Spitz IM, Grunberg SM, Chabbert-Buffet N, Lindenberg T, Gelber H \& Sitruk-Ware R. Management of patients receiving long-term treatment with mifepristone. Fertility and Sterility 2005 84 1719-1726.

40 Grunberg SM, Weiss MH, Russell CA, Spitz IM, Ahmadi J, Sadun A \& Sitruk-Ware R. Long-term administration of mifepristone (RU 486): clinical tolerance during extended treatment of meningioma. Cancer Investigation $2006 \mathbf{2 4} 727-733$. 
41 Grunberg SM, Weiss MH, Spitz IM, Ahmadi J, Sadun A, Russell CA, Lucci L \& Stevenson LL. Treatment of unresectable meningiomas with the antiprogesterone agent mifepristone. Journal of Neurosurgery $1991 \mathbf{7 4} 861-866$.

42 de Keizer RJ \& Smit JW. Mifepristone treatment in patients with surgically incurable sphenoid-ridge meningioma: a long-term follow-up. Eye 200418 954-958.

43 Eisinger SH, Bonfiglio T, Fiscella K, Meldrum S \& Guzick DS. Twelve-month safety and efficacy of low-dose mifepristone for uterine myomas. Journal of Minimally Invasive Gynecology 200512 227-233.

44 Spitz IM. Progesterone antagonists and progesterone receptor modulators: an overview. Steroids 200368 981-993.

45 Chabbert-Buffet N, Meduri G, Bouchard P \& Spitz IM. Selective progesterone receptor modulators and progesterone antagonists: mechanisms of action and clinical applications. Human Reproduction Update 200511 293-307.

46 Klijn JG, de Jong FH, Bakker GH, Lamberts SW, Rodenburg CJ \& Alexieva-Figusch J. Antiprogestins, a new form of endocrine therapy for human breast cancer. Cancer Research 198949 2851-2856.
47 Heikinheimo O, Ranta S, Grunberg S \& Spitz IM. Alterations in sex steroids and gonadotropins in post-menopausal women subsequent to long-term mifepristone administration. Steroids 2000 $65831-836$.

48 Murphy AA, Morales AJ, Kettel LM \& Yen SS. Regression of uterine leiomyomata to the antiprogesterone RU 486: dose-response effect. Fertility and Sterility 199564 187-190.

49 Heikinheimo O, Ranta S, Grunberg S, Lahteenmaki P \& Spitz IM. Alterations in the pituitary-thyroid and pituitary-adrenal axes consequences of long-term mifepristone treatment. Metabolism $199746292-296$.

50 Laue L, Lotze MT, Chrousos GP, Barnes K, Loriaux DL \& Fleisher TA. Effect of chronic treatment with the glucocorticoid antagonist RU 486 in man: toxicity, immunological, and hormonal aspects. Journal of Clinical Endocrinology and Metabolism 199071 1474-1480.

Received 10 July 2007

Accepted 3 August 2007 